\title{
Research on Simulation and Optimization of Tobacco Logistics Center Based on Flexsim
}

\author{
Tian Shihai and Wei Zhiqiang \\ School of Management, Harbin University of Science and Technology, Harbin, \\ China \\ tshttt2004@126.com
}

\begin{abstract}
According to backward technology, tedious process, failure orders and goods queuing of traditional tobacco enterprise logistics center, the process optimization methods is proposed by application of RFID technology. Firstly, actual operating environment of Harbin Tobacco Company (Abbr. HTC) logistics center in China is used as background to analyze the problems existing in the process through investigation. Secondly, the logistics center simulation model is established by using Flexsim simulation technology in order to find out the cause of the problems of logistics center operation process. Finally, operation process of logistics center is optimized. The result shows that the operating efficiency of logistics center has increased by 22.4\%. It proves that the effect of this kind of research method for the optimization of tobacco logistics center process is remarkable and it provides a new way of thinking to implement RFID technology in the logistics center of this industry.
\end{abstract}

Keywords: Tobacco Logistics Center, Simulation Optimization, RFID Technology

\section{Introduction}

As China's first big tax sources, the tobacco industry play the dominant role in the national economy. Most of tobacco companies implement strategies which include enterprise internal construction and management strengthening, external customer resources expansion and business processes optimization to ensure the market competitiveness in recent years. With the increasing of tobacco enterprises, the measures that implemented by companies are no longer cost compression, but logistics system construction strengthening that can increase the profit and enhance the core competitiveness of the enterprise. At present, there are 367 logistics centers of tobacco enterprise in China, and the quantity of new logistics center which built in the past two years is more than 70 [1]. It is easy to know that the government is paying a lot attention to logistics construction of tobacco industry, which will be the next tobacco industry profit growth point.

Some developed countries government pay great importance attention to logistics industry. There are many kinds of high technology used in logistics industry to improve the automation level of logistics center. Vijayaraman and Osyk used RFID technology to optimize the storage process [2]. Yahia studied the supply chain simulation system based on RFID technology, and optimized the logistics distribution business [3]. The most representative countries that have great logistics development in tobacco industry are mainly Europe, the United States and Japan. European and American tobacco logistics use mainly high technology as auxiliary measures to improve the efficiency of the tobacco distribution, such as building automation warehouse, developing logistics information system and so on. Logistics service providers choose the opened fourth party logistics strategy, emphasize the optimization selection of suppliers, and full play the utility of supply chain management system, and establish a good strategic alliance relationship with 
partners to achieve win-win situation. Japan tobacco logistics present highly centralized network coverage forms, in order to control accurate tobacco materials in time. The distribution of tobacco products is in the charge of by special cigarette distribution service providers. In order to save the high cost of self-built logistics center, many foreign manufacturers entrust Japan logistics providers of Tobacco Company to be responsible for distribution. Tobacco sales organization is mainly composed of "operating headquartersoffices-retail" three parts, the selling take the form of phone orders and home delivery service [4].

Due to management method of China's tobacco industry is fall behind relatively, part of the tobacco companies have not built a certain size logistics center equipped with supporting facilities. In 2010 industry symposium, the state tobacco monopoly administration put forward the goal that establish tobacco the Internet of things system, use electronic tag, RFID technology, GIS system to realize the "comprehensive perception, universal coverage, comprehensive promotion". So using the Internet of things technology to optimize tobacco industry is gradually becoming a new technical innovation. Internet of things can make objects in the world connect together by using some key technologies, and can make them initiative to exchange information via the Internet [5]. Tian et al. applied RFID technology in tobacco sorting system to realize the automation of sorting operation, and greatly improved the efficiency of sorting [6]. Shi et al. designed distribution system of Baoji tobacco logistics center in China by using geographic information system [7]. Wang put forward the core of the Internet of things technology implementation of China's tobacco enterprise was the application of RFID technology by analyzing Hangzhou cigarette factories [8]. Wang et al. found application of RFID technology which used in warehouse management could improve the storage efficiency compared with the application of bar code [9]. Thus, application of RFID technology that used in tobacco industry logistics has already been widely recognized. But the researches on how to determine the operation congestion link of the tobacco logistics center, apply RFID technology to optimize process and improve the rate of efficiency after optimizing are relatively insufficient.

So, the logistics center of HTC in China is taken as a research object to determine the congestion link by using Flexsim simulation software to construct model for simulating process of logistics center according to the data of cargo handling, wait time, waiting queue length, the utilization rate of equipment and person in simulation output report, then RFID technology is used to optimize the model.

\section{Process and Problem Analysis of HTC Logistics Center}

\subsection{Layout of HTC Logistics Center}

The logistics center of HTC is the largest tobacco logistics center in province, covers an area of twenty thousand square meters, which has the function of warehousing, sorting and distribution. Figure 1 is the logistics center layout of HTC logistics center.

The logistics center is composed of six work areas: the arrival goods inspection area, warehouse tally, goods storage, outbound sorting area, outbound repeat point area and mobile equipment store. The arrival goods inspection area is responsible for checking the goods of container and truck, and organizing forklift to unload after qualified. The main work of warehousing tally area is coding the goods, plating, classifying and so on. Goods storage area is responsible for the storage of goods and periodic inventory. Outbound sorting area is responsible for the outbound goods classification, selection and barcode scan. Outbound repeat point area is responsible for checking again with outbound goods and allowing outbound after the correct. Mobile equipment store is responsible for parking forklift, carts and many other mobile devices. 


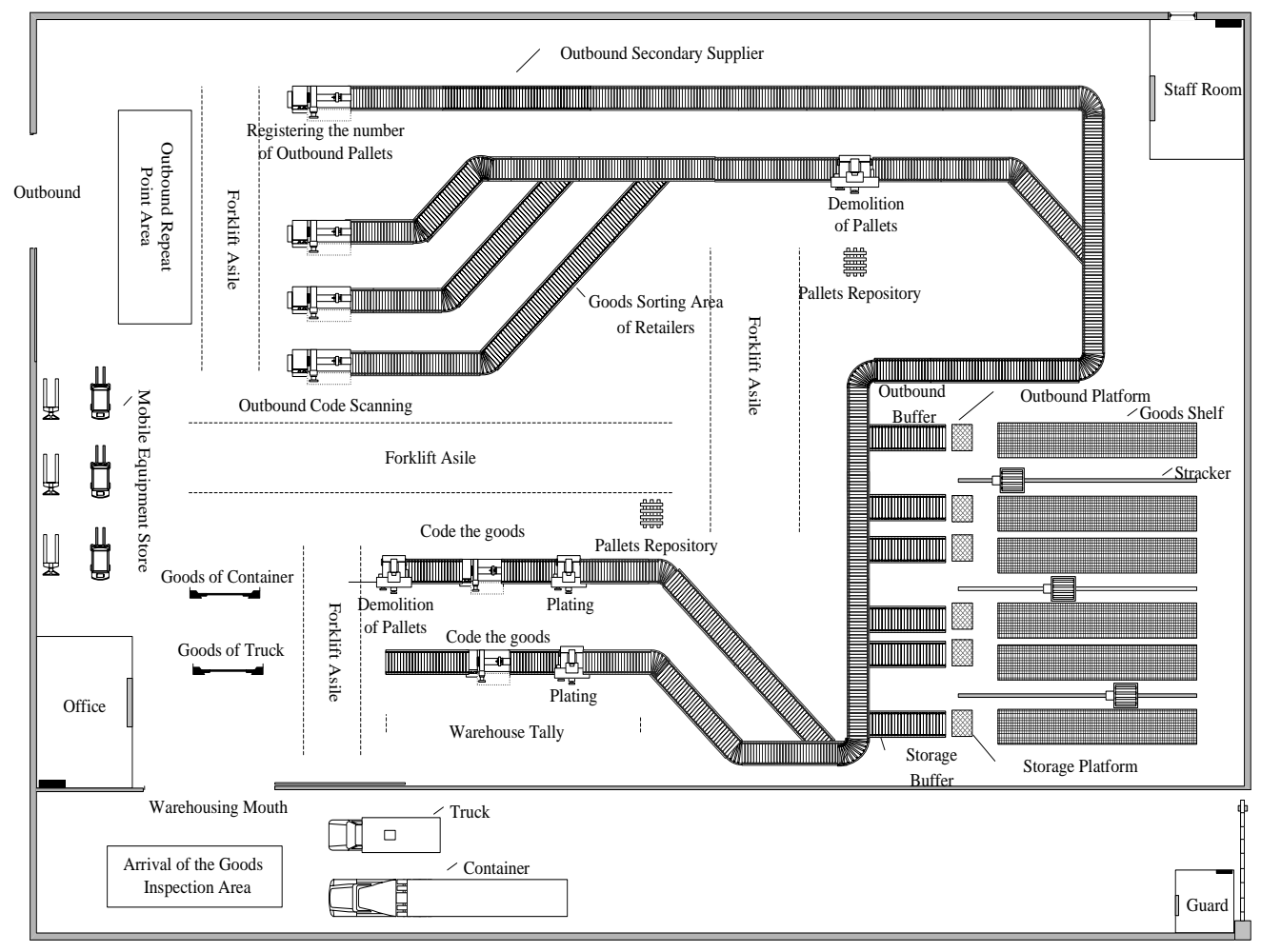

Figure 1. Logistics Center Layout

\subsection{Process of HTC Logistics Center}

The tobacco logistics center is mainly responsible for storage and distribution of cigarette products. The whole process of HTC logistics center is divided into two parts in this paper which include the inbound and the outbound according to the order of cigarette products flow in the center.

(1)Inbound process. There are two ways for cigarette products entering into the logistics center, the one is container type, and another one is box type. Only capacity and barcode scan of the two ways have differences, the inbound processes are basically the same which accepted by inspected person. It includes verifying invoices for testing whether the ticket is complete or not, quantity and variety of the goods are correct or not, then random sampling for testing if any damage and the authenticity of information exists. If inspection is acceptable, it will organize people to unload by forklift truck, or it will be audited and rejected by officer.

After discharge of the container cargo, the cigarette products are transported by the forklift truck to warehouse inbound tally area, and they are transported by the push cart to warehouse inbound tally area after discharge of the goods boxes. The cigarette products are scanned barcode one by one, after that the storing data will be copied into the "number one project" database.

Due to the container loading goods in pallet, barcode scan requires the action of the disassembling pallet, while box type do not need. Finally, according to the location allocation table, the cigarette products are classified. Inbound process is shown in Figure 2. 


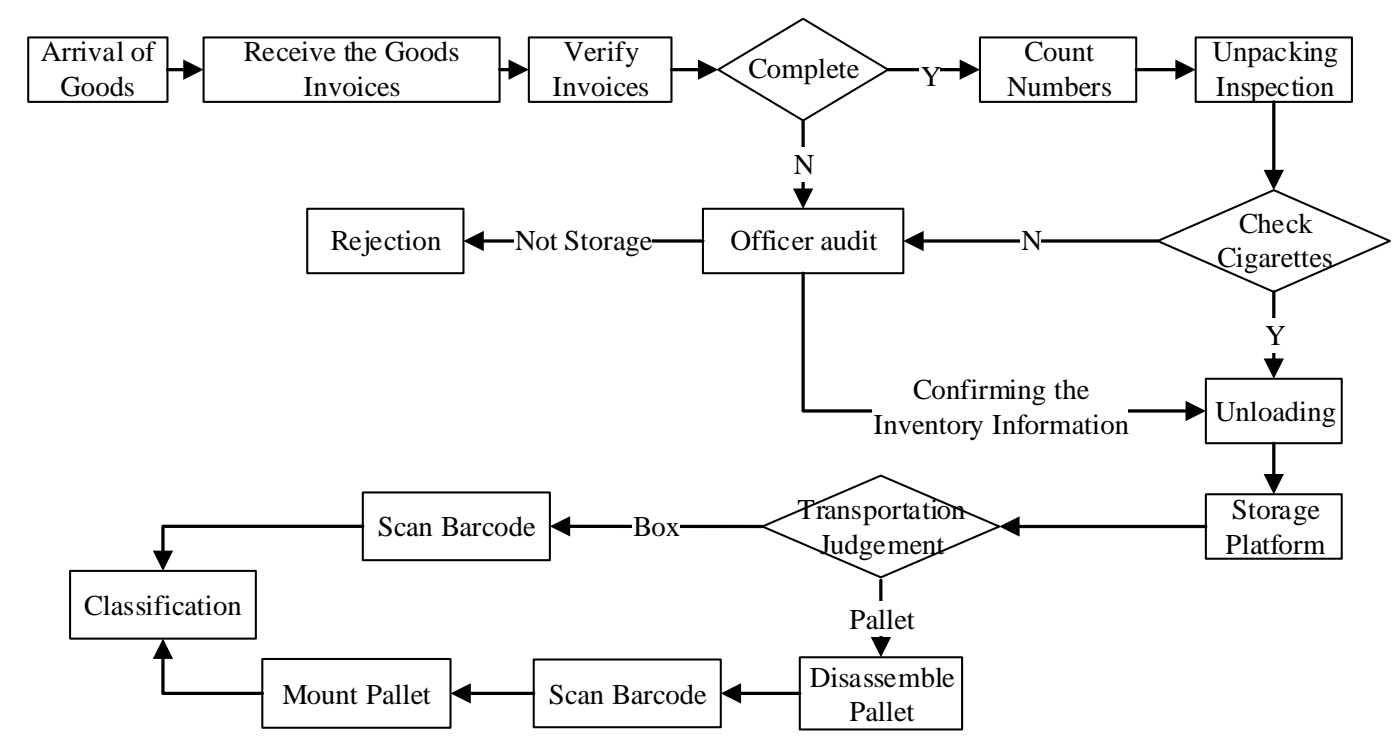

Figure 2. Inbound Process Diagram

(2)Outbound process. As the largest tobacco material distribution center in Heilongjiang province, HTC logistics center not only undertakes the cigarette products reserve and distribution, but also is responsible for secondary supplier orders of surrounding parts of Harbin. Therefore, the outbound process includes retailers' outbound and secondary supplier outbound.

The logistics center of HTC takes the operation mode which is "sorting to the carton, delivery to the door". Because of the quantity of the retailer is huge, and orders are small and scattered, the logistics center's distribution is in carton and package for transportation.

The quantity of secondary supplier orders is bigger, so it can be taken by pallet transportation. These two ways of outbound have some difference in cargo sorting link, but the process is almost same. The staff choose the goods according to the stock requisition in time order, if there are out of stock, they will submit it to officer for auditing, then choose modify or return the order.

The goods picking out are all stay in the outbound staging area. The goods for retailers must be sorted by assembly line after disassembling pallet, registered the outbound information and into the cigarette boxes from different grid automatic, then pasted the retailer's information label by staff. Labeled cigarette products are centralized in outbound repeat point area waiting for second check based on delivery path, and then they will be transported after right checked by staff according to the outbound information and the label information. The outbound process is shown in Figure 3. 


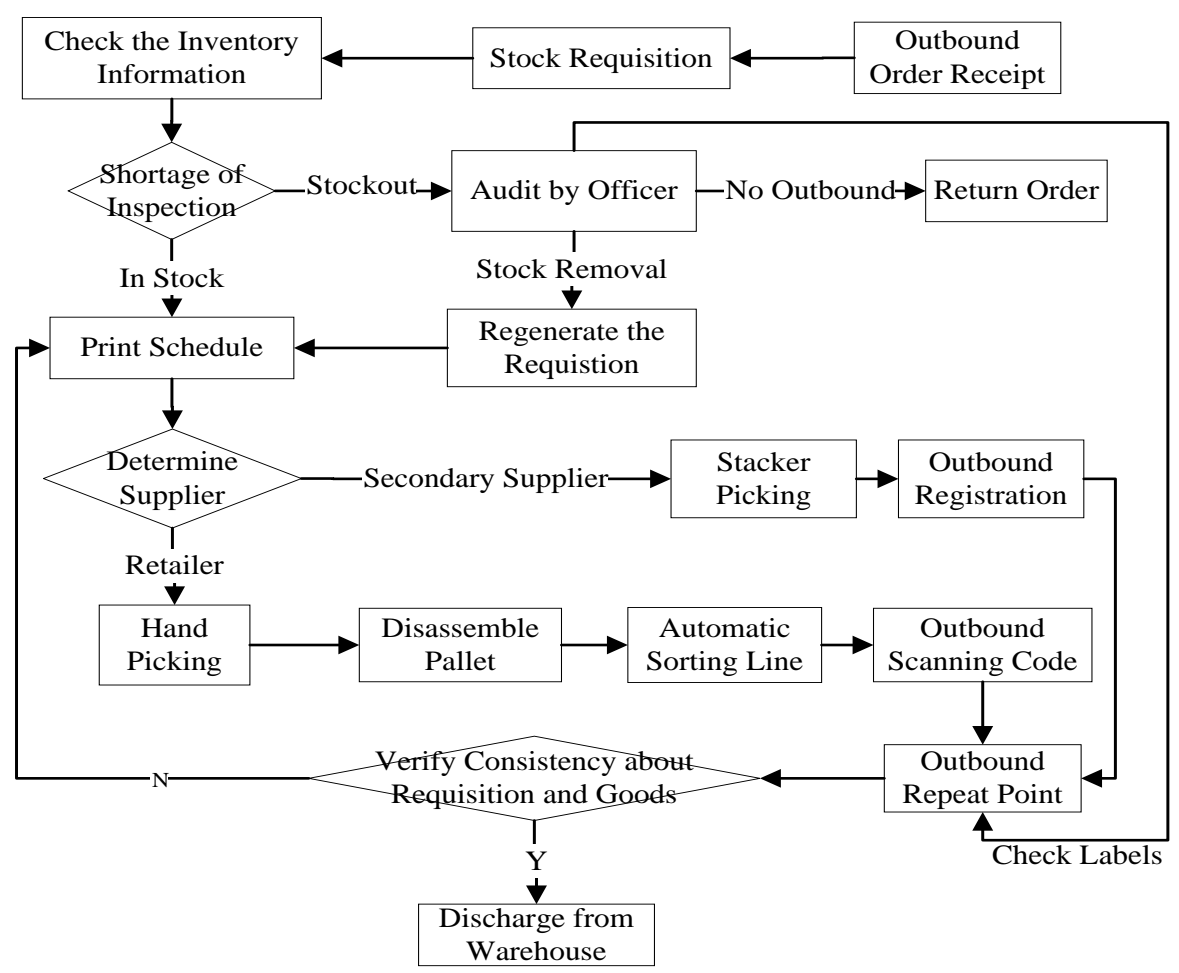

Figure 3. Outbound Process Diagram

\subsection{Problems Existing in the Process of HTC Logistics Center}

It is easy to see that the operation process of logistics center is an order operation process from the Inbound and outbound process diagrams, one link traffic jams will lead to rising the whole operation time. So after research, the tobacco logistics center has the following problems in process:

(1) There is a vehicle queuing phenomenon in the arrival goods inspection area.

(2) Staff and mobile equipment utilization rate is too high.

(3) The accuracy of bar code reading is too low.

(4) The delivery time is longer, orders lack of timeliness.

(5) High Labor costs.

Based on the above problems appeared in practical operation, the simulation model is established on the basis of the existing business processes of logistics center, to find out the bottleneck of logistics center operating mode by analyzing the simulation result.

\section{Simulation Model of HTC Logistics Center Based on Flexsim Software}

\subsection{Simulation Assumptions}

There are two ways for goods arrival which are container type and box type, so the model assumptions are as follows:

(1) The model only simulates cigarette products movement and quantities, not distinguish the type that the goods use.

(2) All goods are not damaged when they arrive, and there is no shortage of phenomenon.

(3) Not considering about equipment's repair, all they can work continually.

(4) Staff quality is no difference and they can work continually, and walking paths are linear 


\subsection{Simulation Model Establishment}

According to the tobacco logistics center layout and business processes, the simulation model established based on Flexsim software is shown in Figure 4.

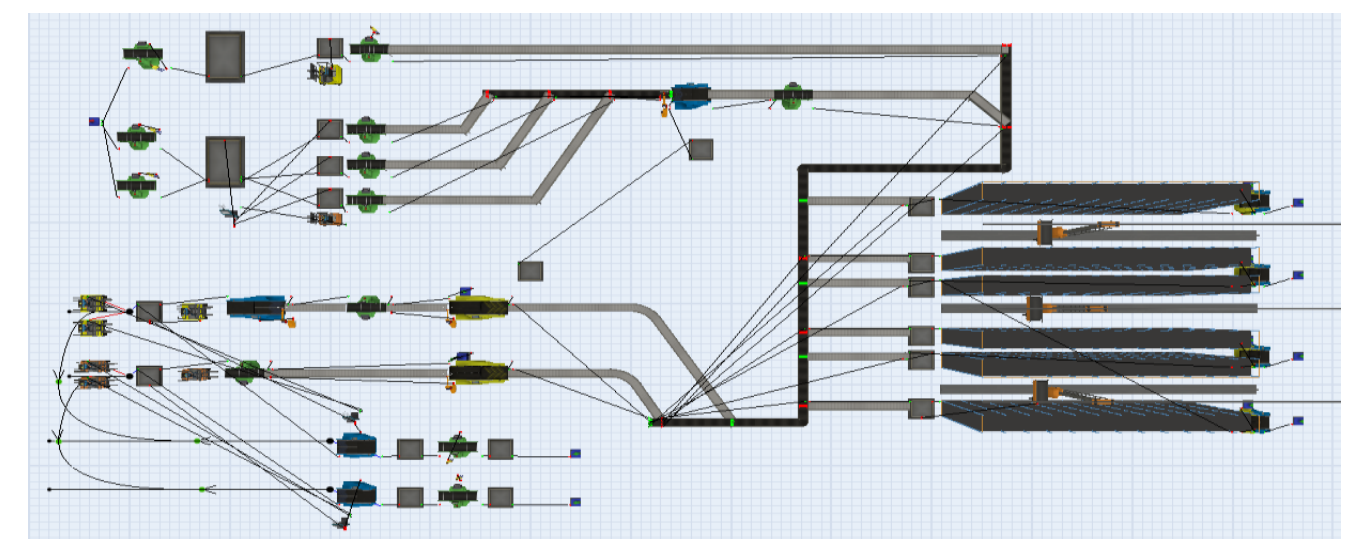

Figure 4. Logistics Center Simulation Model

Because the orders of retailer are in carton, the goods should be disassembled pallet and sorted from three sorting lines. The compiling code for sorting conveyor belt is as follows:

Tree node current=owner object(c);

Tree node item $=$ par node (1);

Int port=parval (2);

Switch (port)

\{

I* process each port in different ways according to the different case */

case 1: return getitemtype $($ item $)==1$;

case 2 : return getitemtype $($ item $)==2$;

case3: return getitemtype $($ item $)==3$;

default: return 1;

\}

return 1;

Because there are so many operation links in the tobacco logistics center, data involved in each link are random data. Therefore, by collecting and analyzing the real-time data of the logistics center, the fitting distribution models of main several operation links can be gotten as follows:

(1)Truck arrival time interval and the retailer order interval are in accordance with uniform distribution.

$$
F(\mathrm{x})=\frac{x-a}{b-a} \quad a \leq x \leq b
$$

$x$ obey uniform distribution in the interval of $[a, b]$, write as $x \sim \operatorname{Uniform}(a, b)$.

(2)Container arrival time interval and the secondary supplier order interval are in accordance with exponential distribution.

$$
f(x \mid \lambda)= \begin{cases}\lambda e^{-\lambda x} & x \geq 0 \\ 0 & x<0\end{cases}
$$

$\lambda>0$ is a parameter of distribution, and $x$ obey exponential distribution in the interval of $[a, b]$, write as $x \sim$ Exponential $(\lambda)$. 
(3)The random variables, such as loading capacity of container and truck, the acceptance time, forklift loading and unloading time, conform to the triangular distribution.

$$
f(x \mid a, b, c)= \begin{cases}\frac{2(\mathrm{x}-\mathrm{a})}{(\mathrm{b}-a)(\mathrm{c}-\mathrm{a})} & a \leq x \leq c \\ \frac{2(\mathrm{~b}-\mathrm{x})}{(\mathrm{b}-\mathrm{a})(\mathrm{b}-\mathrm{c})} & c<x \leq b\end{cases}
$$

$x$ obey triangular distribution in the interval of $[a, b]$ that lower limit is $a$, the mode is $c$, and upper limit is $b$, write as $x \sim$ Triangular $(a, c, b)$.

According to the above analysis, the entity and parameter of each link of the simulation model can be set as shown in Table 1, Table 2 and Table 3.

\section{Table 1. Data of Warehouse Operation}

\begin{tabular}{lll}
\hline Actual operation & Flexsim model entity & Parameters set \\
\hline Container arrival time interval & Source & Exponential(48)min \\
Truck arrival time interval & Source & Uniform $(26,28) \mathrm{min}$ \\
Container loading capacity & Separator & Triangular $(15,20,25) \mathrm{pallet}$ \\
Truck loading capacity & Separator & Triangular $(240,280,400) \mathrm{box}$ \\
Container cargo acceptance time & Processor & Triangular $(15,24,32) \mathrm{min}$ \\
Truck cargo acceptance time & Processor & Triangular $(12,19,27) \mathrm{min}$ \\
Forklift loading time & Transporter & Triangular $(60,100,140) \mathrm{sec} / \mathrm{pallet}$ \\
Forklift unloading time & Transporter & Triangular $(5,10,15) \mathrm{sec} / \mathrm{pallet}$ \\
Forklift loading time into warehouse & Transporter & Triangular $(5,10,15) \mathrm{sec} / \mathrm{pallet}$ \\
loading time & Transporter & Triangular $(1.5,2.5,3.5) \mathrm{sec} / \mathrm{box}$ \\
Cart loading time into warehouse & Transporter & Triangular $(5,10,15) \mathrm{sec} / \mathrm{cart}$ \\
\hline
\end{tabular}

Table 2. Data of Outbound Operation

\begin{tabular}{lll}
\hline Actual operation & Flexsim model entity & Parameters set \\
\hline Retailers order interval & Source & Uniform(25,29)min \\
Secondary supplier order interval & Source & Exponential(36)min \\
Quantity of Retailer orders & Separator & Triangular(140,180,230)box \\
Quantity of Secondary supplier orders & Separator & Triangular(6,7,8)pallet \\
Picking time & Combiner & Triangular(4,5,7)min/pallet \\
Pallet quantity of Retailers outbound & Processor & 5sec/pallet \\
registration & & \\
Barcode scan and registration of the secondary & Processor & Triangular $(80,120,200) \mathrm{sec} /$ \\
supplier outbound & & pallet \\
Barcode of retailers outbound & Processor & 2sec/box \\
Forklift loading time of outbound & Transporter & Triangular(5,10,15)sec/ pallet \\
Cart loading time of Outbound & Transporter & Triangular $(5,10,15) \mathrm{sec} / \mathrm{cart}$ \\
Second check time of retailer goods & Processor & Triangular $(15,20,27) \mathrm{sec} / \mathrm{box}$ \\
Second check time of secondary supplier goods & Processor & Triangular $(60,80,100) \mathrm{sec} /$ \\
\end{tabular}

Table 3. Other Relevant Data

\begin{tabular}{lll}
\hline Actual operation & Flexsim model entity & Parameters set \\
\hline Manipulator moving time & Robot & $1.5 \mathrm{~m} / \mathrm{sec}$ \\
Barcode scanning time & Processor & $2 \mathrm{sec}$ \\
Staff walking speed & Operator & $1 \mathrm{~m} / \mathrm{sec}$ \\
Forklift operating speed & Transporter & $2 \mathrm{~m} / \mathrm{sec}$ \\
Cart operating speed & ASRSvehicle & $1 \mathrm{~m} / \mathrm{sec}$ \\
Belt transmission speed & Conveyor & $1 \mathrm{~m} / \mathrm{sec}$ \\
Sorting belt transmission speed & MergeSort & $1 \mathrm{~m} / \mathrm{sec}$ \\
Shelves storage allocation & Rack & $1 \mathrm{pallet} /$ allocation \\
\hline
\end{tabular}


The operation time of tobacco logistics center is 8:00-17:00 which has an hour lunch break. To set up simulation model's working time is 28800 seconds, run the model and record the results.

\section{Results Analysis and Optimization of Simulation Model}

\subsection{Results Analysis of Simulation Model}

According to Setting the parameters of model and compiling each entity, the results of the model operation derived after operating eight hours as shown in Table 4.

Table 4. Result Report of Model Entities Operating

\begin{tabular}{|c|c|c|c|c|c|c|}
\hline Entity & Action & Input & $\begin{array}{l}\text { Outp } \\
\text { ut }\end{array}$ & $\begin{array}{l}\text { Average } \\
\text { waiting } \\
\text { time } \\
(\mathrm{sec})\end{array}$ & $\begin{array}{l}\text { Average } \\
\text { waiting } \\
\text { queue } \\
\text { length }\end{array}$ & $\begin{array}{l}\text { Use } \\
\text { rate }\end{array}$ \\
\hline \multirow{5}{*}{ Truck } & Waiting for acceptance & 21 & 21 & 8.53 & 0.89 & ------ \\
\hline & Acceptance time & 21 & 20 & 1117.07 & ------ & $80.75 \%$ \\
\hline & $\begin{array}{l}\text { Waiting for the } \\
\text { warehouse }\end{array}$ & 5753 & 5571 & 366.91 & 182 & ----- \\
\hline & Barcode scan & 5753 & 5753 & 3.42 & 0 & $69.39 \%$ \\
\hline & Assembling pallet & 5900 & 5900 & 4.82 & 0 & $99.97 \%$ \\
\hline \multirow{6}{*}{$\begin{array}{l}\text { Contain } \\
\text { er }\end{array}$} & Waiting for acceptance & 9 & 9 & 0 & 0.46 & $\begin{array}{l}----- \\
\end{array}$ \\
\hline & Acceptance time & 9 & 9 & 1333.11 & ----- & $48.03 \%$ \\
\hline & $\begin{array}{l}\text { Waiting for the } \\
\text { warehouse }\end{array}$ & 168 & 161 & 894.15 & 7 & ----- \\
\hline & Disassembling pallet & 161 & 6412 & 61.09 & 28 & $66.64 \%$ \\
\hline & Barcode scan & 6412 & 6409 & 2.84 & 3 & $63.15 \%$ \\
\hline & Assembling pallet & 6570 & 6569 & 4.38 & 1 & $99.99 \%$ \\
\hline \multirow{6}{*}{$\begin{array}{l}\text { Transpo } \\
\text { rtation } \\
\text { machine }\end{array}$} & Unloading forklift 1 & 83 & 83 & 33.73 & ------ & $47.78 \%$ \\
\hline & Unloading forklift 2 & 85 & 85 & 33.97 & ------ & $46.88 \%$ \\
\hline & Unloading cart 1 & 2883 & 2883 & 117.81 & ----- & $64.52 \%$ \\
\hline & Unloading cart 2 & 2870 & 2870 & 117.80 & ------ & $64.37 \%$ \\
\hline & Warehouse forklift & 161 & 161 & 13.94 & ------ & $15.95 \%$ \\
\hline & Outbound cart & 2960 & 2920 & 158.51 & ------ & $79.01 \%$ \\
\hline \multirow{5}{*}{$\begin{array}{l}\text { Retailer } \\
\mathrm{s}\end{array}$} & Order quantity & 17 & 3039 & 713.90 & 69.16 & $\begin{array}{l}----- \\
\end{array}$ \\
\hline & Picking time & 3039 & 3115 & 9.19 & & $63.66 \%$ \\
\hline & $\begin{array}{l}\text { Waiting for second } \\
\text { check }\end{array}$ & 2920 & 2540 & 1784.85 & 97.77 & ------ \\
\hline & Second check staff 1 & ------ & ------ & ------ & ------ & $91.14 \%$ \\
\hline & Second check staff 2 & ------ & ------ & ------ & ------ & $91.06 \%$ \\
\hline \multirow{4}{*}{$\begin{array}{l}\text { Seconda } \\
\text { ry } \\
\text { supplier } \\
\text { s }\end{array}$} & Order quantity & 12 & 82 & 1031.99 & 123.85 & ------ \\
\hline & Picking time & 82 & 82 & 8.49 & 1 & $78.49 \%$ \\
\hline & $\begin{array}{l}\text { Waiting for second } \\
\text { check }\end{array}$ & 80 & 80 & 0 & 0 & ------ \\
\hline & Second check staff & ------ & ------ & ------ & ------ & $22.88 \%$ \\
\hline
\end{tabular}

Through the analysis of the simulation output result, the fact is found that truck arrives 21 times, but acceptance just only 20 times in the work hour, there are one truck didn't finish the inspection. The staff has to work overtime to finish the truck acceptance, because the truck acceptance time is too long and the average acceptance time is 1117.07 seconds.

The average waiting time of boxes-typed goods in the warehouse tally is 366.91 seconds, waiting queue length is 182 cases, and average barcode scanning and pallet 
assembling time is 8.24 seconds. Average waiting time of container-typed goods in the warehouse tally is 894.15 seconds, waiting queue length is 7 pallets, and there are queuing phenomenon existing in disassembling, assembling pallet and scanning barcode, so the equipment need to work overtime to complete warehousing work. It shows that the main reasons of congestion are that the action of disassembling and assembling pallet is too cumbersome, and scanning time is too long.

In the outbound process, the orders that retailers issued are 17, but only picked 16, the average waiting time of picking is 713.90 seconds. The orders that secondary suppliers issued are 12 , overall 82 pallets, but only 80 pallets arrived the outbound repeat point area, there are 2 pallets didn't finish the check, so the reason why order handing efficiency is too low is easy to be seen. Because of picking time is too long, the average waiting time of retailer's goods is 1784.85 seconds, and waiting queue length is 97.77 boxes in the outbound repeat point area. There still exist goods waiting phenomenon in the case of $91 \%$ person utilization rate. So seeking the methods to reduce second check time and improve the efficiency of check is important at present.

\subsection{Business Process Optimization}

It is known that the bottleneck link of HTC logistics center's process is inbound acceptance in which acceptance time, disassembling pallet time, assembling pallet time and outbound picking time are too long. At the same time, second check procedure is too tedious. Except the fixed time of stuff and equipment, the main time-consuming link is judgment and registration of the goods information in the whole work procedure.

Based on the above problems, using RFID technology for HTC to decrease the judgment and registration time of goods, save manpower and material resources cost, and optimize the working flow of logistics center. As the key technology of the Internet of things implementation, RFID technology has broken the disadvantages of traditional bar code technology easily damaged, information not repeatable and long scan time, meanwhile, realized the advantages of data quick writing and reading, information realtime sharing, not affected by the external environment pollution, high data security [10]. The implementation of RFID technology includes the application of equipment and technologies, such as electronic tags, stationary read/write device, handheld read/write device, and warehouse management system and so on [11-12]. The specific application is as follows:

(1)Upper tobacco production enterprises stick electronic tag containing the information of goods on the package container, so that the logistics center can read and track cargo information quickly.

(2)Installing stationary read/write device at the entrance of inbound and outbound to read quickly and accurately the quantity, type and other information of goods.

(3)Sticking the electronic tag on the pallet, so that it could feedback items information at any time.

(4)The various mobile devices of logistics center are installed stationary read/write device, at the time of transporting goods, it can be read or change the item information, and realize the tracking of mobile devices.

(5)Sticking electronic tags on each shelf of logistics center, so that it could locate goods information quickly when choosing the order. After the application of RFID technology, the overall business process is shown in Figure 5. 


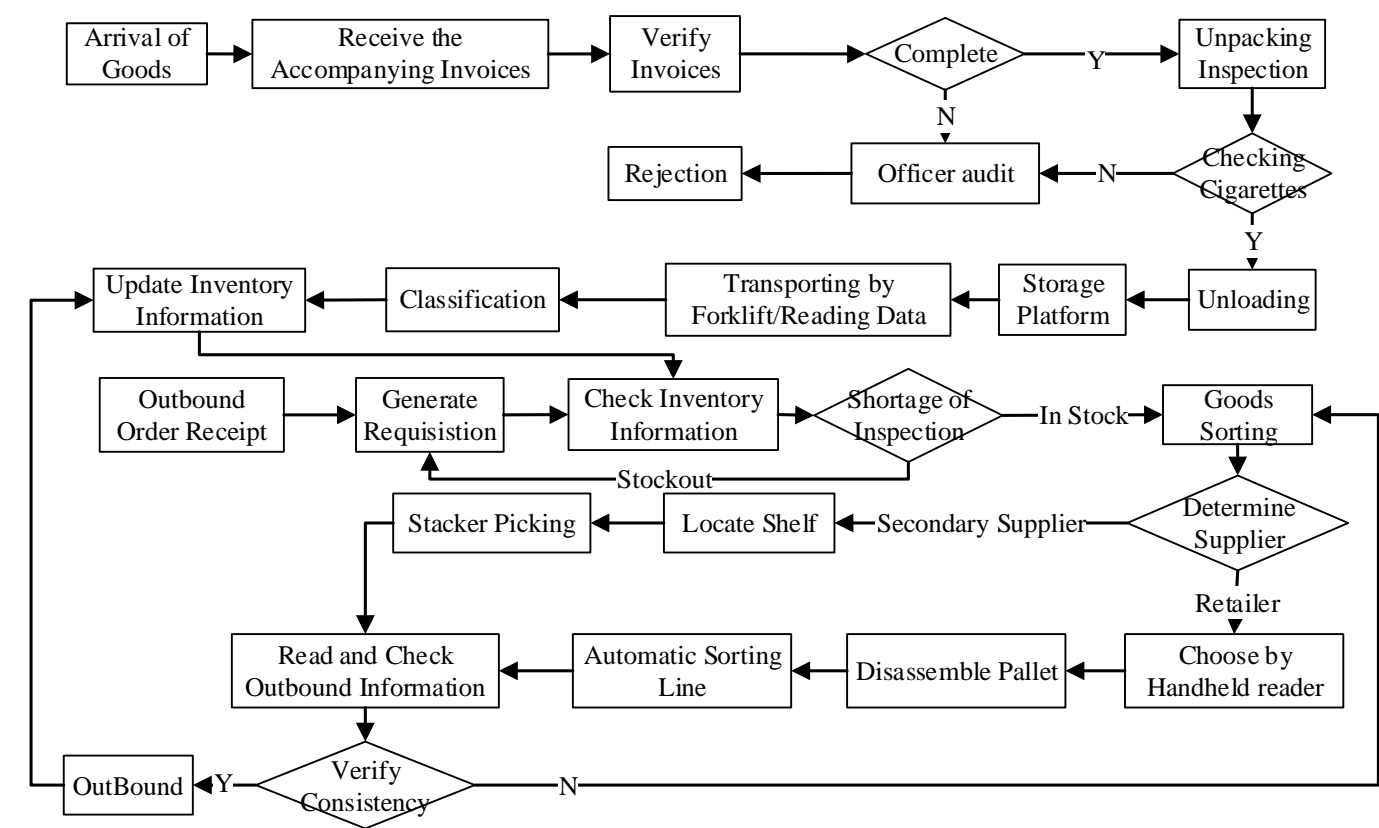

Figure 5. Logistics Center Business Flow Diagram Based on RFID Technology

\subsection{Simulation Model of HTC Logistics Center Based RFID Technology}

According the work process influenced by RFID technology and the shorter time rate after RFID application, the parameters can be reset as shown in Table5.

\section{Table 5. Relevant Data of Optimization Model}

\begin{tabular}{ll}
\hline Actual operation & Parameters set \\
\hline Container cargo acceptance time & Triangular(10,16,21)min \\
Truck cargo acceptance time & Triangular( $7,12,15) \mathrm{min}$ \\
Picking time & Triangular(2.5,3.5,4.5)min/ pallet \\
Pallet quantity of Retailers outbound registration & 0 \\
Barcode of retailers outbound & 0 \\
Second check time of secondary supplier goods & $0.1 \mathrm{sec}$ \\
\hline
\end{tabular}

The construction of logistics center optimized simulation model by using RFID technology is shown in Figure 6.

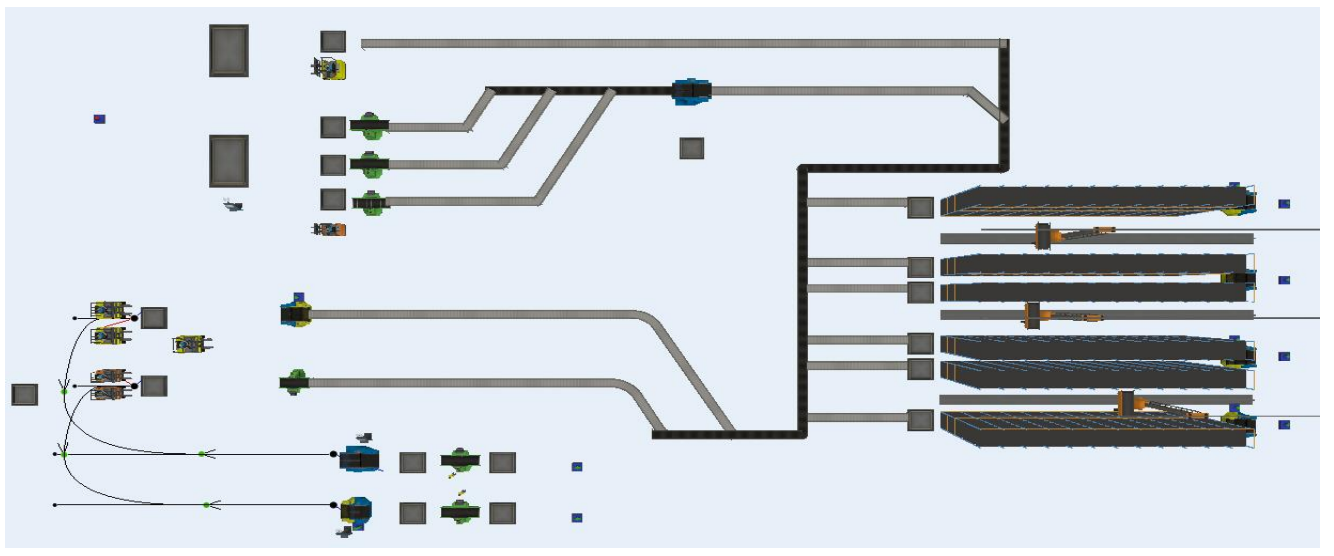

Figure 6. Logistics Center Simulation Model Based on RFID Technology 
Setting and compiling the parameter of optimized simulation model, comparing the results with original model after running 8 hours, the compared results about order completion rate, goods waiting time and stuff working time are shown in the Figure 7, Figure 8 and Figure 9.

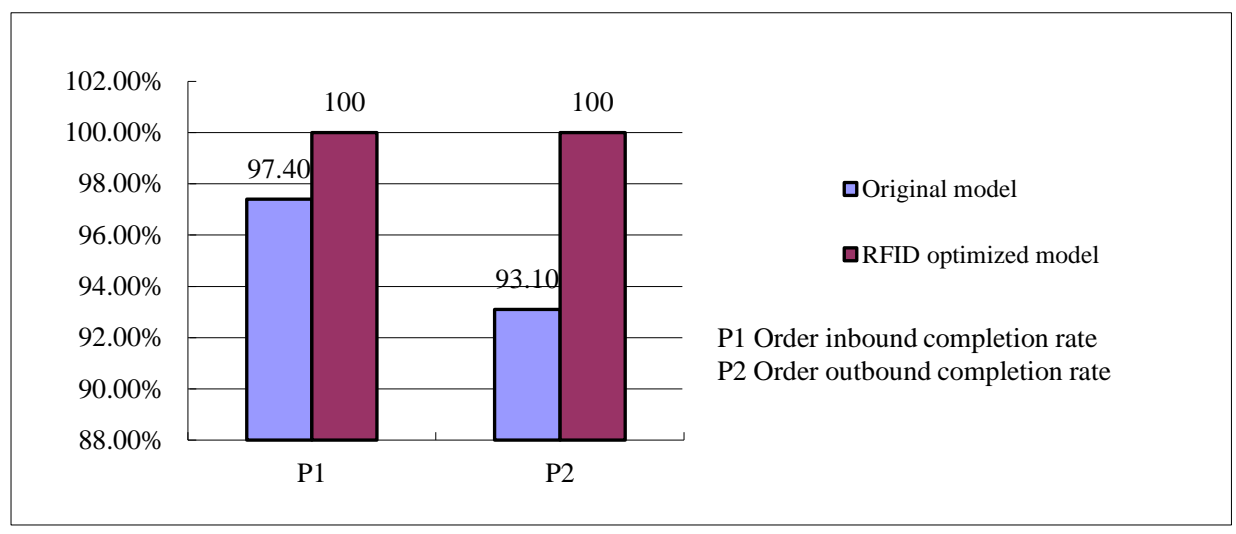

Figure 7. Comparison of Order Completion Rate

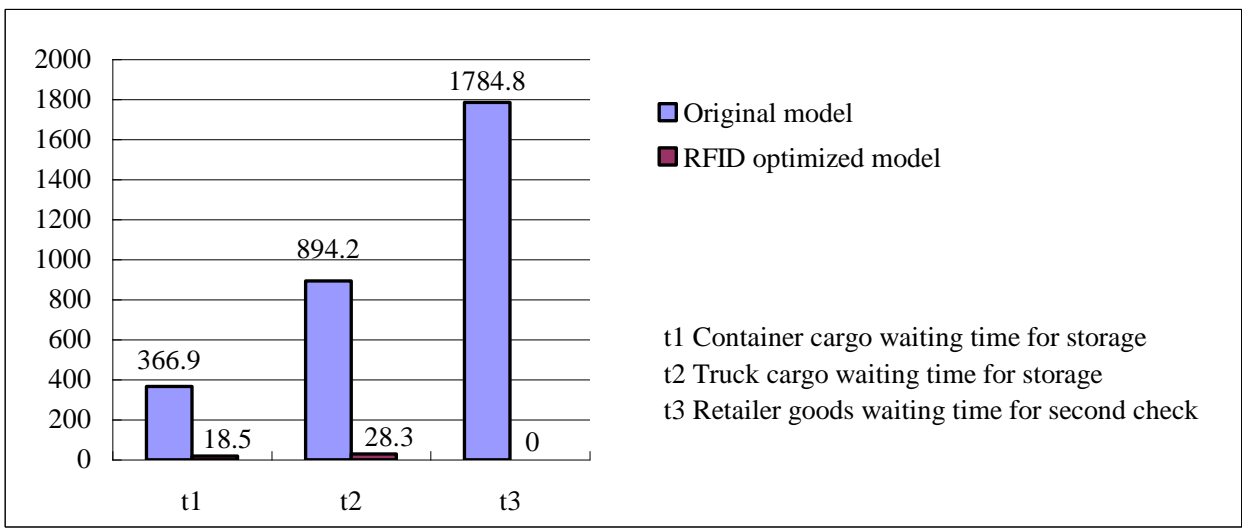

Figure 8. Comparison of Waiting Time for the Goods (Time/Second)

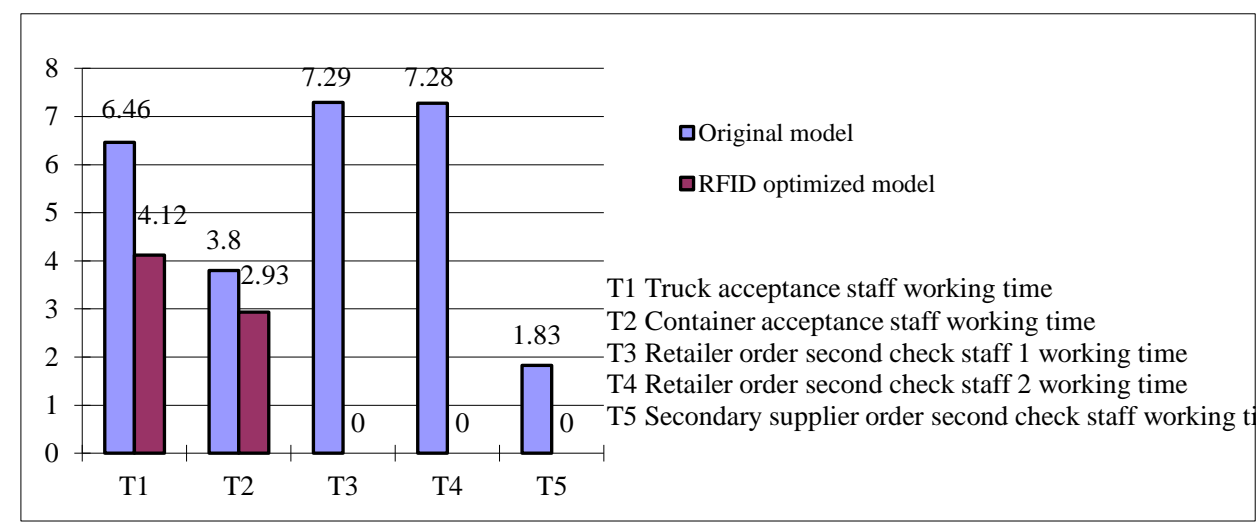

Figure 9. Comparison of Stuff Working Time (Time/Hour)

By comparative analysis of the model results, it can be found that all bottleneck problems of the original model have been solved completely. Within 8 hours working time, inbound and outbound operation can be completed, the ability of order controlling improved, goods waiting time greatly reduced, and inspector workload had decreased too. 
Due to the repeat point area without manual operation, it also saves the human cost for logistics center.

\section{Conclusions}

As an industry with special business model, China tobacco industry has a complete structure and function of the supply chain, although its production and marketing form different by comparing with other industries, and the ultimate goal is also to satisfy the customer demand and achieve the maximize profits. HTC logistics center is given as an example to find that the original process has many problems such as long acceptance time, pallet action time consuming, long picking time, second check block queuing and so on, by surveying, analyzing, modeling and simulating. These problems lead to some phenomenon which includes vehicle queuing, inbound and outbound process tedious, stuff and equipment utilization rate unreasonable. The introduction of RFID equipment and technology can solve the above problems and save the labor cost, time and manpower, increase the order processing ability. It provides a new idea and method for the simulation and optimization of tobacco industry logistics center.

\section{Acknowledgment}

The research work was supported by Natural Science Foundation of Heilongjiang province of China (G201203, G201302), Postdoctoral Scientific Research Foundation of Heilongjiang province of China (LBH-Q12065), Philosophy Social Sciences Innovation Team Building Plan of Universities in Heilongjiang province (TD201203).

\section{References}

[1] M. He, "Tobacco logistics development direction in China", Cooperative Economy and Technology, vol. 9, (2011), pp. 67-68.

[2] B. S. Vijayaraman and B.A. Osyk, "An empirical study of RFID implementation in the warehousing industry", The International Journal of Logistics Management, vol. 17, no. 1, (2006), pp. 6-20.

[3] Z. M. Yahia, "RFID-enabled Supply Chain Systems with Computer Simulation", Assembly Automation, vol. 29, no. 2, (2009), pp. 174-183.

[4] T. Zhen, Y.H. Zhu and Q.W Zhang, "A RFID logistics resource management system for the warehouse ", International Conference on Environment Science and Information Application Technology, vol. 2, (2009), pp. 63-66.

[5] Y. Ma, "Features and application of Internet of Things", The Internet of Things Technology, vol. 8, (2012), pp. 78-80.

[6] J.H. Tian, Y. S. Fan and Y.L. Zhu, "Design of tobacco logistics sorting system based on RFID", Journal of Instrument, vol. 27, no.6, (2006), pp. 1875-1886.

[7] Y. R. Shi, D. F. Wan and S. Y. Li, "Research of vehicle routing problem based on GIS", Systems Engineering Theory and Practice, vol. 29, no. 10, (2009), pp. 76-84.

[8] H.W. Wang, "The advice of Internet of things technology application of tobacco industry", Logistics and Material Handing, vol. 12, (2011), pp. 108-111.

[9] B. Wang, Y. P. Qin, G. Q. Bian and X.N. Qun, "Application and study of RFID technology in warehouse and logistics management for tobacco companies", Internet of things technology, no. 1, (2013), pp. 84-87.

[10] W. S. Ron, "RFID: A technical overview and its application to the enterprise", IT Professional, vol. 7, no.3, (2005), pp. 27-33.

[11] L.M. Wang, S.L. Ge and Y.P. Jiang, "Manufacturing inventory system analysis and design on basis of RFID", Manufacture Information Engineering of China, vol. 37, no.3, (2007), pp. 7-14.

[12] K.F. Jin, "Design and Implementation of Tobacco Input/output Warehouse Management System Based on RFID”, Computer Knowledge and Technology, vol. 7, no. 4, (2011), pp. 813816. 


\section{Authors}

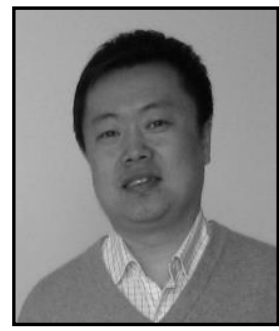

Tian Shihai, born in 1972. He is a professor of Harbin University of Science and Technology in China. His research interests include data mining, distributed systems, distributed algorithms, virtual enterprise and logistics simulation research.

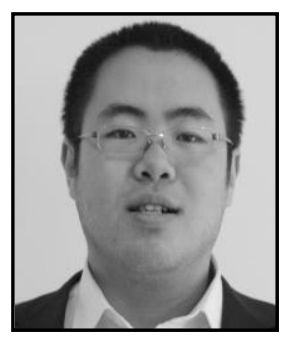

Wei Zhiqiang, mainly research on data mining, distributed systems, adaptive prediction algorithms, cloud computing and the internet of things. 
International Journal of $u-$ and e- Service, Science and Technology Vol.9, No. 5 (2016) 